\title{
Relationship of Developmental Stage of Cantaloupe Fruit to Black Rot Susceptibility and Enzyme Production by Didymella bryoniae
}

\author{
J. X. Zhang and B. D. Bruton, United States Department of Agriculture, Agricultural Research Service, South \\ Central Agricultural Research Laboratory, Lane, OK 74555; M. E. Miller and T. Isakeit, Department of Plant Pa- \\ thology and Microbiology, Texas A\&M University, Weslaco, TX 78596
}

\begin{abstract}
Zhang, J. X., Bruton, B. D., Miller, M. E., and Isakeit, T. 1999. Relationship of developmental stage of cantaloupe fruit to black rot susceptibility and enzyme production by Didymella bryoniae. Plant Dis. 83:1025-1032.

Black rot of cantaloupe fruit, caused by Didymella bryoniae, can be severe when environmental conditions and fruit developmental stages are favorable for infection. Symptoms of black rot on cantaloupe fruit varied greatly depending on fruit age. The black rot phase was observed only on mature fruit. Inoculation of cantaloupe fruit at different developmental stages with five $D$. bryoniae isolates resulted in the greatest amount of decay on 10-day-old fruit compared with 20-, $30-, 40-$, or 50-day-old fruit. There was no difference in lesion size among 20-, 30-, 40-, or 50day-old fruit, although there was variation in lesion size among fungal isolates. Five fungal isolates all produced the greatest polygalacturonase (PG) activity in inoculated 10-day-old fruit compared with 20-, 30-, 40- or 50-day-old fruit. There was a positive correlation between lesion size and total fungal PG activity in decayed tissue. Using a representative D. bryoniae isolate (OK 963096), multiple PG isozymes were detected in both fungal shake culture and decayed fruit. Eleven PG isozymes (pI 4.7 to 7.9) were detected from fungal shake culture using pectin or polygalacturonic acid as the sole carbon source. Twelve PG isozymes (pI 4.7 to 8.7) were detected from decayed tissue of 10-day-old fruit, and 13 PG isozymes (pI 4.2 to 8.7) were observed from decayed tissue of 50-day-old fruit. The activity of $D$. bryoniae PG produced in vitro and in vivo was optimum at pH 5.0 and 5.5, respectively. The activity of the fungal PG produced in vitro exhibited primarily an endo-mode of action. In contrast, PG extracted from decayed tissue was predominately exo-PG. Thus, PG may play an important role in pathogenesis of $D$. bryoniae during cantaloupe fruit decay.
\end{abstract}

Additional keywords: Cucumis melo var. cantaloupensis, fruit rot, pectolytic enzymes

Gummy stem blight and black rot, caused by Didymella bryoniae, is a highly destructive disease on leaves, stems, flowers, and fruits of cucurbits worldwide $(36,46)$. The disease is recognized as gummy stem blight in the crown and stems of cucurbits and as black rot on the fruit. The black rot phase can be severe on butternut squash, acorn squash, buttercup squash, and Hubbard pumpkins (46). Black rot of cucumbers in which colonization of the fruit frequently develops without any visible symptom on the surface was reported as one of the most important dis-

Corresponding author: B. D. Bruton

E-mail: bbruton-usda@lane-ag.org

Mention of a trademark, proprietary product, or vendor does not constitute a guarantee or warranty of the product by the USDA and does not imply its approval to the exclusion of other products of vendors that may also be suitable.

Accepted for publication 30 July 1999.

Publication no. D-1999-0921-02R

This article is in the public domain and not copyrightable. It may be freely reprinted with customary crediting of the source. The American Phytopathological Society, 1999. eases in glasshouse cucumber production in Denmark, Poland, Sweden, and the Netherlands $(17,18,25,37,38)$. In the Lower Rio Grande Valley (LRGV) of Texas, gummy stem blight infrequently occurs in the crown of cantaloupe (Cucumis melo var. cantaloupensis), but rarely on honeydew (C. melo var. inodorus) $(10,30)$. The leaf spot phase is occasionally observed on leaves of cantaloupe as triangular lesions.

In the spring of 1997, an outbreak of gummy stem blight and black rot of cantaloupe fruit occurred in the LRGV of Texas as a result of unusually cool and wet weather during March and April (30). Black rot was observed on all fruit developmental stages, ranging from the initial stages of net development (approximately 12 days postpollination) to mature fruit. Many cantaloupe fields had $100 \%$ fruit loss (30). Fields with the greatest incidence of black rot were those that had melons in the early stages of net development during the cool-wet weather of March and April. In addition, more than $90 \%$ of $D$. bryoniae isolates recovered from cucurbits were benomyl resistant (30). Much of the research on gummy stem blight of cantaloupe has focused on fungal physiology $(12,13)$, genetics (23), host resistance
$(29,45)$, and fungicidal control $(30,39)$. Although $D$. bryoniae has been described on stems, leaves, and fruit of many cucurbits, there is little information describing black rot on cantaloupe fruit. The mechanisms of cantaloupe fruit infection and decay with respect to fruit developmental stages are largely unknown.

This study was undertaken to determine: (i) symptoms of fruit rot in the field and on inoculated cantaloupe fruit at different developmental stages; (ii) susceptibility of fruit at different developmental stages to decay caused by $D$. bryoniae; (iii) relationship between size of fruit lesion and fungal polygalacturonase (PG, EC 3.2.1.15) production; and (iv) partial characterization of fungal PG produced in culture and decayed fruit.

\section{MATERIALS AND METHODS}

Field surveys and fungal isolates. Cantaloupe fruit from approximately 10 fields in the LRGV of Texas were collected during May 1997. Fruit exhibiting external lesions were cut perpendicularly to the lesion to determine the depth of the lesion. On the remainder of each fruit, the epidermal layer (approximately $2 \mathrm{~mm}$ ) was removed to expose lesions that had no obvious external symptoms. The various symptoms were noted, and isolations from lesions were made on potato dextrose agar (PDA) to confirm the causal agent.

All isolates were grown on PDA at $25^{\circ} \mathrm{C}$ for 4 days, hyphal tipped, and transferred to glass vials containing autoclaved moist artificial soil mix (Scotts, Marysville, $\mathrm{OH}$ ) for long-term storage $\left(23^{\circ} \mathrm{C}\right)$. The fungal isolates were recovered for each study by sprinkling a small aliquot of the funguscolonized artificial soil from the storage vials onto PDA and incubating for 4 days at $25^{\circ} \mathrm{C}$. Five $D$. bryoniae isolates were arbitrarily selected for use in this study. Isolates OK 963095 and OK 963096 were originally obtained from naturally infected cantaloupe fruit at the Lane Research Station at Lane, Oklahoma. Isolates TX 97046, TX 97072, and TX 97128 were obtained from naturally infected cantaloupe fruit from commercial fields in the LRGV of Texas.

Shake culture of the pathogen. A modified Richard's medium (27) containing $10 \mathrm{~g}$ of $\mathrm{KNO}_{3}, 5 \mathrm{~g}$ of $\mathrm{KH}_{2} \mathrm{PO}_{4}, 2.5 \mathrm{~g}$ of $\mathrm{MgSO}_{4} \cdot 7 \mathrm{H}_{2} \mathrm{O}, 0.02 \mathrm{~g}$ of $\mathrm{FeCl}_{3} \cdot 6 \mathrm{H}_{2} \mathrm{O}, 1$ liter of distilled water, and a carbon source 
was used to culture the fungus. The carbon source was either $1 \%(\mathrm{wt} / \mathrm{vol})$ citrus pectin (Sigma, St. Louis, MO) or 1\% (wt/vol) polygalacturonic acid (Sigma). The $\mathrm{pH}$ of the medium was 4.0 for either pectin or polygalacturonic acid as the carbon source. Two 7-mm PDA disks of D. bryoniae (isolate OK 963096) were introduced into each 250-ml flask containing $100 \mathrm{ml}$ of autoclaved medium and placed on an orbital shaker $(100 \mathrm{rpm})$ at $25^{\circ} \mathrm{C}$. There were four replicate flasks for each treatment. Five-ml aliquots were aseptically withdrawn from each flask at 2, 4, 6, and 8 days. At day 10, the contents of each flask were filtered through Miracloth (Calbiochem-Behring, La Jolla, CA). Filtrates were centrifuged at $32,000 \times g$ for $15 \mathrm{~min}$, and the supernatants were collected and stored at $-20^{\circ} \mathrm{C}$ until needed for enzyme assays. The mass of mycelia collected on the Miracloth was oven-dried at $70^{\circ} \mathrm{C}$ for 7 days and weighed. The experiment was repeated.

Inoculation of fruit at different developmental stages. Cantaloupe (cv. Magnum 45) were grown at the Lane Research Station using recommended cultural practices. Female flowers were tagged at the day of flowering. Harvested fruit were inoculated at 10, 20, 30, and 40 days (horticultural maturity) postpollination. Additional fruit were harvested at 40 days and stored 10 days at $4{ }^{\circ} \mathrm{C}$ (hereafter noted as 50-day fruit). Five $D$. bryoniae isolates (OK 963095, OK 963096, TX 97046, TX 97072, and TX 97128) were grown on $\mathrm{PDA}$ at $25^{\circ} \mathrm{C}$ for 4 days prior to fruit inoculation. Fruit were inoculated by surface-disinfesting the melon with $80 \%$ ethanol and removing tissue aseptically $(1 \mathrm{~cm}$ deep) with a cork borer $(0.7 \mathrm{~cm}$ diameter). A PDA disk $(0.5 \mathrm{~cm}$ diameter $)$ colonized by the fungus was placed into each inoculation site followed by a small autoclaved cotton ball and sealed with Kwik Seal Caulk (DAP Inc., Dayton, OH). Three to five inoculation sites were established on each fruit, and five fruit were used for each isolate. Fruit inoculated using the same procedure with PDA plugs without the fungus served as controls. After 4 days, each lesion was cut perpendicularly, and the profiles of the lesions were traced on transparency sheets. The area of decay was calculated using an area meter (Li-Cor, Lincoln, NE). Decayed and healthy tissue were collected and stored at $-20^{\circ} \mathrm{C}$ until processed for enzyme extraction. The experiment was done twice.

PG activity and isozyme assays. Proteins were extracted from decayed and healthy fruit tissue. Ten grams of decayed or healthy tissue was placed in $10 \mathrm{ml}$ of 0.1 $\mathrm{M}$ Na-acetate buffer ( $\mathrm{pH}$ 5) containing $1 \mathrm{M}$ $\mathrm{NaCl}$ and $1 \mathrm{mM}$ EDTA in a centrifuge tube. The mixture was homogenized for 1 min using a polytron (Kinematica, Littau, Switzerland). The homogenates were centrifuged at $32,000 \times g$ for $15 \mathrm{~min}$, and the supernatants were collected and stored at $-20^{\circ} \mathrm{C}$ until processing. PG activity of the supernatants was assayed by measuring reducing groups using the 2-cyanoacetamide method (19). The substrate was $0.2 \%$ polygalacturonic acid in $50 \mathrm{mM} \mathrm{Na}-$ acetate buffer ( $\mathrm{pH}$ 5.0). The reaction mixture consisting of $50 \mu \mathrm{l}$ of each sample (four replicates) with $150 \mu \mathrm{l}$ of substrate was incubated for $30 \mathrm{~min}$ at $40^{\circ} \mathrm{C}$. The reaction was terminated by adding $1.2 \mathrm{ml}$ of $0.1 \mathrm{M}$ borate buffer ( $\mathrm{pH}$ 9) containing $0.2 \%$ 2-cyanoacetamide and boiling for 10 min. The absorbance of the samples at 276 nm was detected using a spectrophotometer (Shimadzu Inc., Kyoto, Japan) after the reaction mixture was equilibrated to room temperature. Controls (zero time), in which the terminating buffer was added prior to the substrate solution, were run simultaneously with each sample. Galacturonic acid was used to establish a standard curve. One unit of enzyme activity was defined as one $\mu$ mole of reducing groups released by the enzyme per min at $40^{\circ} \mathrm{C}$. Protein was determined using a protein assay kit (BioRad, Hercules, CA) with bovine serum albumin as the standard used according to the manufacturer.

To detect PG isozymes, isoelectric focusing-polyacrylamide gel electrophoresis (IEF-PAGE) of extracted proteins was conducted on the Multiphor II apparatus (Pharmacia Biotech, Alameda, CA) according to the procedure described previously (43). PG analysis was determined from fungal cultural supernatants and from protein extracts of decayed or healthy fruit tissue. The samples were desalted with a PD-10 column containing Sephadex G-25 (Sigma) and concentrated 5 to 10 times using a Centriprep concentrator (Amicon, Beverly, MA) with a 10,000 molecular weight cut-off membrane. IEF gel $(0.5 \mathrm{~mm}$ thickness) contained $6.8 \%$ total acrylamide (Pharmacia Biotech), $0.21 \%$ N, N'-methylenebisacrylamide (Pharmacia Biotech), and 2\% ampholine ( $\mathrm{pH} 3.5-10$, Pharmacia Biotech). Equal amounts of PG (0.01 unit) from different PG samples were loaded on each gel. Proteins $(10 \mu \mathrm{g}$ of protein per loading) extracted from healthy fruit (10 or 50 days old) were applied on the gel and served as the controls. PG isozymes were detected as described by Ried and Collmer (34). After IEF-PAGE of proteins was completed, the running gel was immersed in Na-acetate buffer $(0.1 \mathrm{M}, \mathrm{pH} 5)$ for 5 min and then overlaid with a pectate-agarose gel $(0.5 \mathrm{~mm}$ thickness) containing $1 \%$ agarose (catalog no. A-6877, Sigma) and $0.1 \%$ polygalacturonic acid with $0.1 \mathrm{M} \mathrm{Na}-$ acetate, $\mathrm{pH}$ 5.0. Overlaid gels were incubated at $40^{\circ} \mathrm{C}$ for $2 \mathrm{~h}$, stained with $0.05 \%$ ruthenium red for approximately $15 \mathrm{~min}$, and washed with distilled water for $15 \mathrm{~min}$. The gels were dried at room temperature. The assays were conducted at least three times. The pIs of PG isozymes were determined using a pI calibration kit $(\mathrm{pH} 3-$
10, Pharmacia Biotech). The pI markers were run on the same gel as PG samples. Immediately after IEF-PAGE of proteins was completed, lanes with $\mathrm{pI}$ markers were excised and stained with Coomassie blue.

Optimum $\mathrm{pH}$ and mode of action of D. bryoniae PG activity. Optimum $\mathrm{pH}$ for D. bryoniae (isolate OK 963096) PG activity was determined by assaying PG activity, as previously described, over a $\mathrm{pH}$ range from 1 to 12 with four replicates. PG samples were obtained from fungal shake culture (10 days) using pectin as the sole carbon source or from fungal decayed fruit tissue (10 days old). The substrate $(0.2 \%$ polygalacturonic acid) was used in conjunction with different buffers to obtain the desired $\mathrm{pH}$. The buffers $(0.1 \mathrm{M})$ consisted of the following: Glycine-HCI, pH 1 and 2;

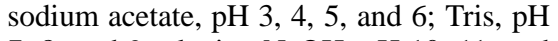

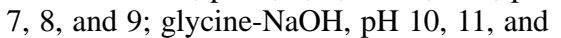
12. Boiled PG samples were run for each $\mathrm{pH}$ simultaneously as controls.

The endo- or exo-mode of PG activity of D. bryoniae (isolate OK 963096) in vitro or in vivo was determined by the reduction of viscosity and the analysis of hydrolysis products. The assays were conducted using protein extracts from decayed fruit (10 days old) or fungal shake culture filtrates (10 days old) using pectin as the sole carbon source. The PG samples were desalted with a PD-10 column packed with Sephadex G-25 (Sigma). Viscosity measurement of the reaction mixture containing 4.5 $\mathrm{ml}$ of $1 \%$ polygalacturonic acid in $0.1 \mathrm{M}$ Na-acetate buffer ( $\mathrm{pH} 5.0$ ) and $0.5 \mathrm{ml}$ of each PG sample (from in vitro or in vivo) was mixed in a Cannon-Fenske viscometer (size 100). The viscosity was measured every $30 \mathrm{~min}$ for $4 \mathrm{~h}$. The identical mixture containing $1 \%$ galacturonic acid rather than polygalacturonic acid served as a control to calculate viscosity reduction. Simultaneously, the percentage of substrate hydrolysis was determined by the reducing group assay described previously, assuming the substrate was $100 \%$ galacturonide. The products formed in the reaction mixtures were detected as follows: During the viscosity test described above, 40- $\mu$ l aliquots were obtained at $0,0.5,1,2,3$, and 4 $\mathrm{h}$, respectively, and boiled for $30 \mathrm{~min}$. Ten $\mu \mathrm{l}$ of each boiled enzyme reaction was spotted on a thin-layer chromatography (TLC) plate coated with silica gel $(250-\mu \mathrm{m}$ thickness, Whatman, Clifton, NJ). Mono-, di-, and tri-galacturonic acid $(0.5 \% \mathrm{wt} / \mathrm{vol}$, Sigma) in distilled water were used as standards, respectively. Hydrolytic products released by PG were separated and visualized on the TLC plates according to the method described by Yao et al. (42). The experiment was conducted twice with three replicates.

Data analysis. Analysis of variance of the data was performed by a general linear model procedure (SAS Institute, Cary, NC). The correlation between fruit decay and fungal PG activity was analyzed using 
a regression model of SAS. Treatment means were compared using the RyanEinot-Gabriel-Welsch multiple range test $(P \leq 0.05)$.

\section{RESULTS}

Fruit decay and symptoms. D. bryoniae caused severe cantaloupe fruit losses in the LRGV of Texas during the spring of 1997 , producing a variety of symptoms on the fruit. Specific symptoms were not necessarily associated with the stage of fruit development, except for the black rot phase on mature fruit. Infection on immature fruit appeared as a light brown discoloration in the developing net. As a result of infection, the net in the affected area usually did not fully develop. In many cases, the only external symptom exhibited on the fruit was a brown discoloration of the net, which was surrounded by green irregular areas that could be observed when the fruit began to lose some of the chlorophyll. In some cases, part of the net in the affected area disintegrated and eroded away (Fig. 1A). Cantaloupe fruit nearing maturity often exhibited a fissure with a green halo surrounding the lesion (Fig. 1B) which was strikingly similar to Fusarium fruit rot (Fig. 1C). In contrast to Fusarium fruit rot, where the tissue immediately surrounding the lesion was tan to brown and often raised and corky, the tissue surrounding the black rot lesion was tan to brown and corky but not raised. Pycnidia and pseudothecia were not produced in black rot lesions on cantaloupe fruit. In many cases, fissures in the fruit were not present, and the only signs of infection were the tan to brown discoloration of the net in the affected area with incomplete net development and surrounded by dark green blotches (Fig. 1D). A cross-section of the fruit through the lesion revealed a firm, dry, burnt umber colored lesion that penetrated into the orange flesh, especially where fissures in the fruit occurred (Fig. $1 \mathrm{E})$. Internal lesions tended to be asymmetrical with multiple lobes. In general, the lesions remained within 2 to $3 \mathrm{~mm}$ of the epidermis, although some extended into the seed cavity, especially those where the fruit had split. Occasionally the fungus penetrated deeper into the mesocarp, exhibiting irregular white feathery areas below the lesion (Fig. 1F). On mature fruit, an external black discoloration in the lesion area was frequently observed, although there was no mycelial growth on the surface. Black discoloration of the internal lesion was not normally observed until the fruit were near maturity (Fig. 1G). In honeydew fruit, black rot lesions were rarely observed except for occasional lesions at the blossom scars (Fig. $1 \mathrm{H})$. Similar lesions were observed at the stylar end on cantaloupe fruit.
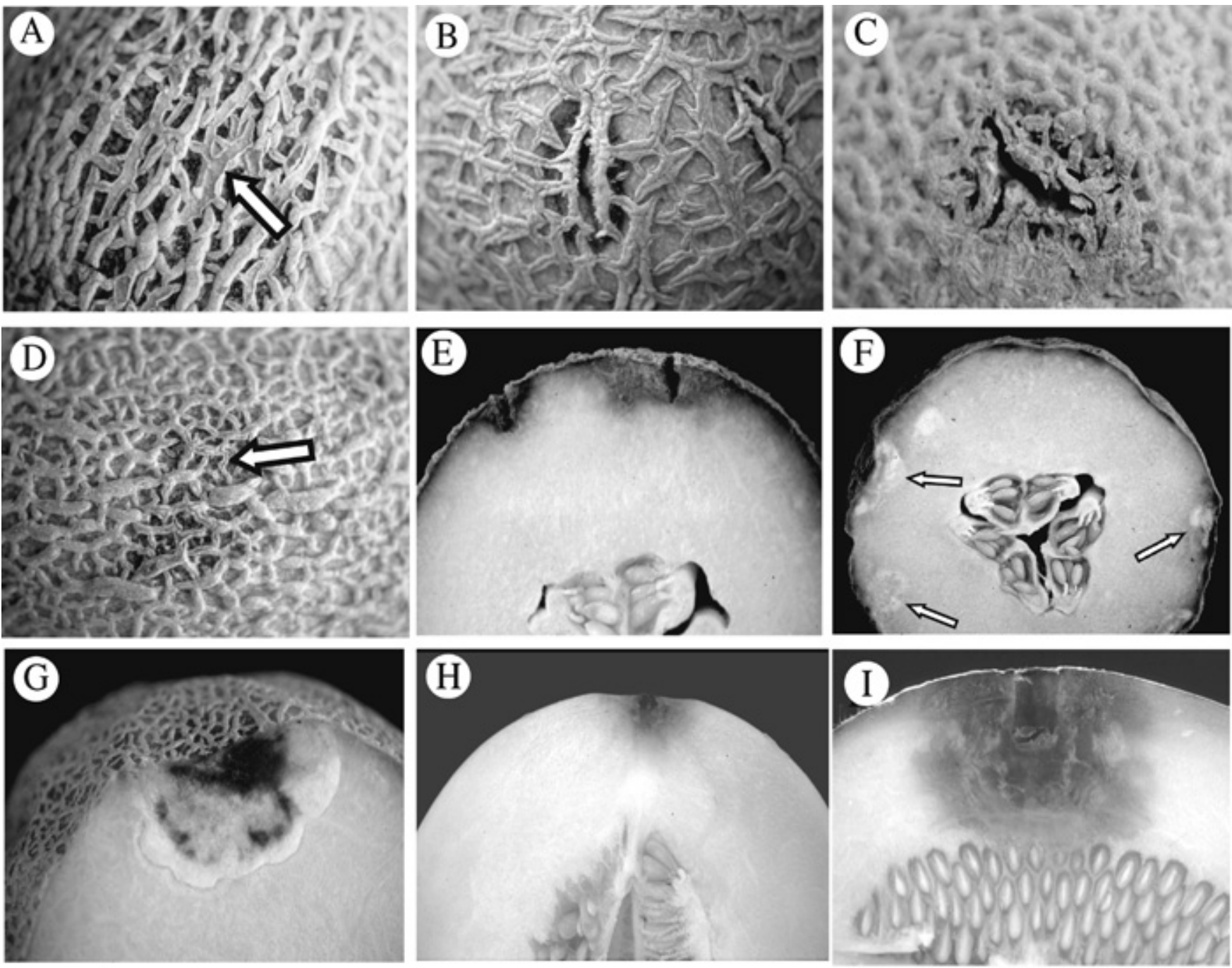

Fig. 1. Symptoms of black rot of cantaloupe and honeydew fruit caused by natural infection or artificial inoculation of Didymella bryoniae with a comparison to the typical symptom caused by Fusarium semitectum. (A) disintegrated net (note arrow) on a cantaloupe fruit; (B) fissure along the net of cantaloupe fruit surrounded by a green halo caused by D. bryoniae; (C) fissure along the net of cantaloupe fruit with a green halo (caused by F. semitectum); (D) incomplete net development (note arrow) with green island; (E) cross-section of cantaloupe fruit showing fissures in the fruit with the irregular, dry, brown lesion in the mesocarp; (F) cross-section of cantaloupe fruit showing white feathery internal lesions (note arrows); (G) cross-section of mature cantaloupe fruit showing a black lesion surrounded by lobes of white growth; $(\mathbf{H})$ cross-section of honeydew fruit showing infection of the stylar end; and (I) cross-section of 10 day postpollination cantaloupe fruit 4 days after artificial inoculation showing a brown, water-soaked, irregular, and nondistinct lesion. 
Symptoms of black rot under artificial inoculation conditions were generally similar to those produced under natural conditions. Lesions on 10-day-old fruit were water-soaked, brown-mottled, and asymmetrical, with no distinct margin between diseased and healthy tissue (Fig. 1I). The lesions on 20- to 50-day-old inoculated fruit were relatively dry, generally symmetrical, dark brown to black at the inoculation site surrounded by a white halo, and formed a distinct lesion.

Fruit decay in relation to developmental stage. Fruit at the developmental stage of $10,20,30,40$, or 50 days postpollination were individually inoculated with the five isolates of $D$. bryoniae. All isolates were pathogenic, causing decay on each age group of fruit tested. Area of decay was significantly $(P \leq 0.05)$ greater on 10 day-old fruit than on 20-, 30-, 40-, or 50day-old fruit (Fig. 2A). The area of the lesion on 20- through 50-day-old fruit was similar $(P \leq 0.05)$. Regression analysis showed that fruit age was negatively cor- related $(r=-0.4214, P=0.0002)$ with area of fruit lesion in inoculated fruit, and the interaction between fungal isolates and fruit ages was not significant $(P=0.9918)$.

Fruit decay in relation to fungal PG production. PG activity was detected in extracts of decayed tissue (10 to 50 days old) 4 days after inoculation with each of the five $D$. bryoniae isolates (Fig. 2B). No PG activity was detected from the extracts of healthy fruit at all developmental stages tested (10 to 50 days postpollination). Although there was variation in PG activity in decayed fruit tissue among the five $D$. bryoniae isolates, each isolate produced the greatest PG activity in inoculated 10-dayold fruit compared with 20-, 30-, 40- or 50day-old fruit (Fig. 2B). PG activity detected in $D$. bryoniae-inoculated fruit at developmental stages of $20,30,40$, or 50 days postpollination was not different $(P \leq$ $0.05)$. The average $P G$ activity of the five $D$. bryoniae isolates produced in 10-dayold fruit was approximately $68 \%$ greater than that in 20-, 30-, 40-, or 50-day-old fruit. Fruit developmental stages were negatively correlated $(r=-0.3961, P=$ $0.0004)$ with total fungal PG activity in decayed fruit. Production of PG in decayed fruit was positively correlated $(r=0.7226$, $P=0.0001)$ with the area of decay in inoculated fruit (Fig. 3).

Characterization of $D$. bryoniae PG isozymes extracted from in vitro and in vivo. D. bryoniae isolate OK 963096 was grown in shake culture using either pectin or polygalacturonic acid as the sole carbon source. PG activity was detected in filtrates from both carbon sources and increased over the 10-day study (Fig. 4). The PG activity using pectin was 2.5-, 3.3-, and 5.5-fold greater $(P \leq 0.05)$ than that with polygalacturonic acid at 6,8 , and 10 days, respectively.

At least 11 D. bryoniae (OK 963096) PG isozymes (pI 4.7 to 7.9) were observed from shake culture using polygalacturonic acid or pectin as the carbon source (Fig. 5, lanes 2 and 3). D. bryoniae produced similar PG isozymes on both carbon sources. Based on the intensity of PG bands on IEF gel (Fig. 5, lanes 2 and 3), isozymes with pI 6.1, 6.4, 6.7, 7.2, and 7.9

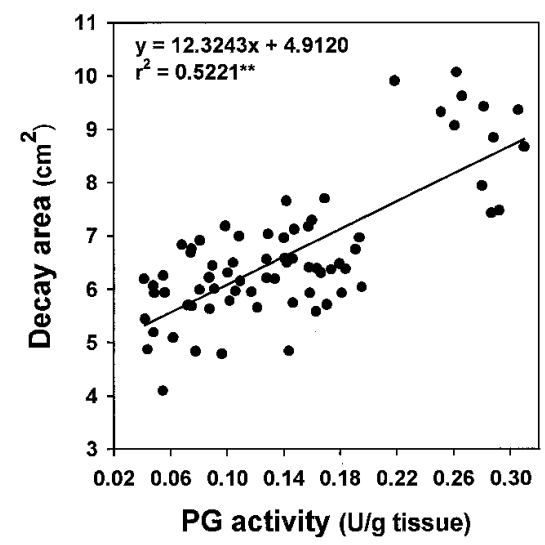

Fig. 3. Correlation between lesion area caused by Didymella bryoniae and fungal polygalacturonase activity in decayed cantaloupe fruit tissue.

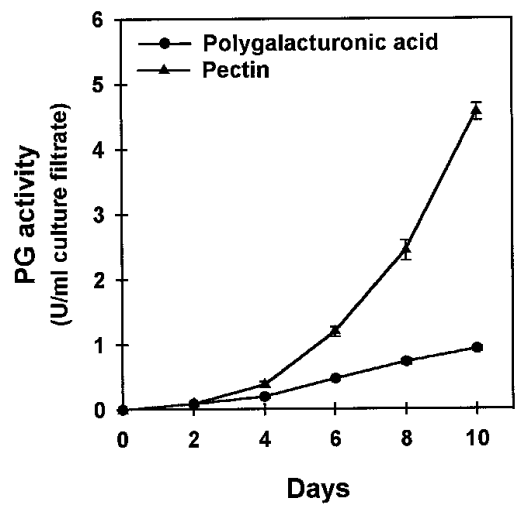

Fig. 4. Total polygalacturonase activity of Didymella bryoniae (OK 963096) produced over time in shake culture using pectin or polygalacturonic acid as the sole carbon source. Bars indicate standard error of four replicates.
Fig. 2. Developmental stages of cantaloupe fruit inoculated with the five selected isolates of Didymella bryoniae illustrating (A) area of lesion 4 days after inoculation and (B) polygalacturonase activity produced by the fungus in decayed fruit tissue. Bars indicate standard errors of four replicates.
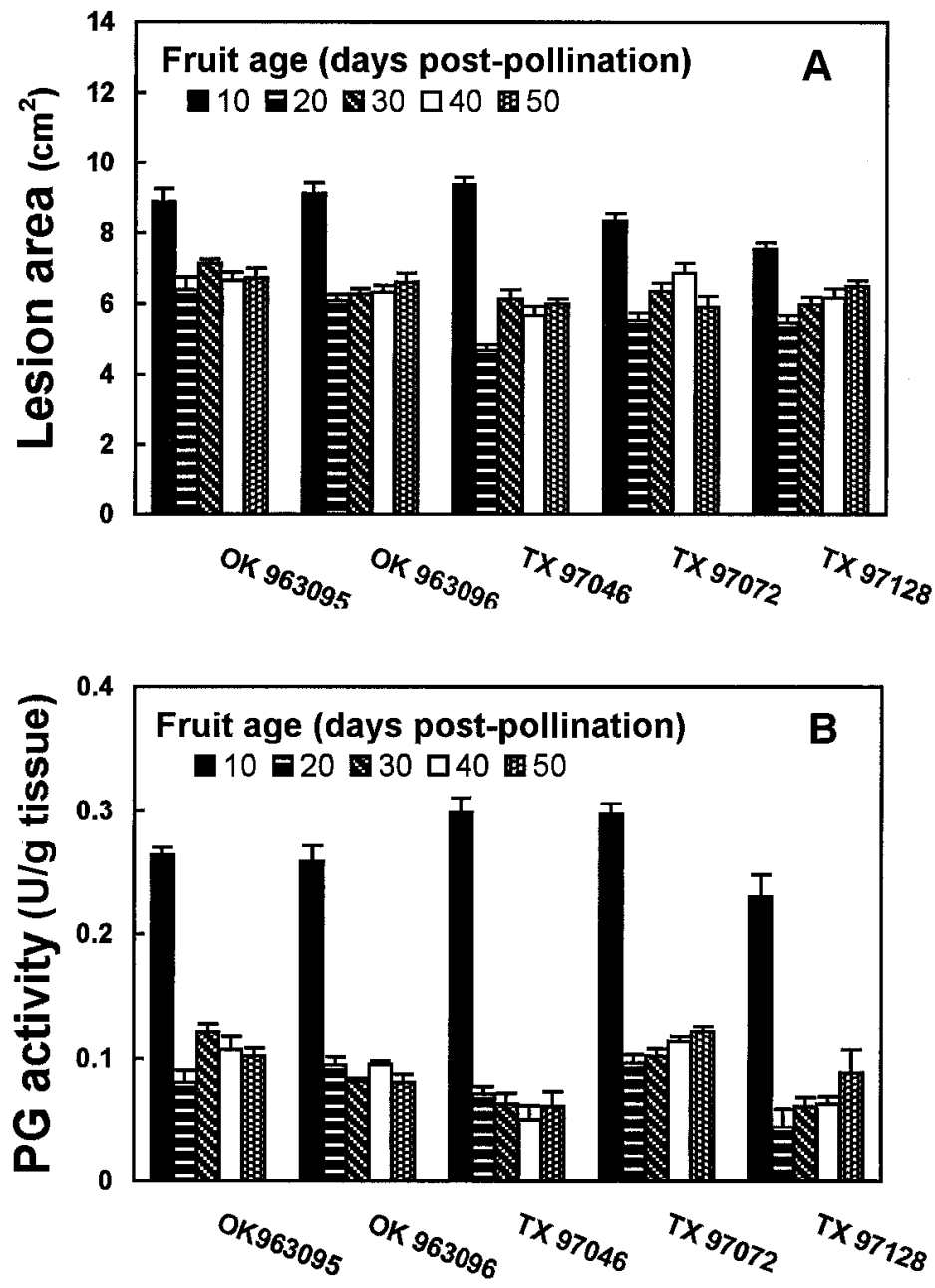

\section{Fungal isolates}


were more active or in higher concentrations than isozymes with pI 4.7 to 5.9.

Twelve PG isozymes, with a $\mathrm{pI}$ range of 4.7 to 8.7 , were detected from extracts of 10-day-old fruit 4 days after inoculation with isolate OK 963096 (Fig. 5, lane 5). Thirteen PG isozymes with pI 4.2 to 8.7 were observed from the extract of 50-dayold fruit 4 days after inoculation with the fungus (Fig. 5, lane 8). No PG was detected from healthy fruit from 10 days or 50 days postpollination (Fig. 5, lane 6 and 9). Fungal PG isozymes produced in $20-$, 30 -, or 40-day-old fruit were similar to those of 10-day-old fruit (data not shown). PG isozymes produced by $D$. bryoniae in decayed fruit at 10 and 50 days postpollination were similar except that the PG isozyme with pI 4.2 was only observed from fungal decayed tissue in 50-day-old fruit (Fig. 5, lanes 5 and 8). The fungal PG isozymes with pI 7.2, 7.6, and 7.9 detected from 10-day-old fruit were more active or in higher concentrations than the rest of $\mathrm{PG}$ isozymes based on the intensity of PG bands on IEF gel.

Optimum pH and mode of action of PG activity produced by $D$. bryoniae in vitro and in vivo. The optimum $\mathrm{pH}$ for the activity of PG produced by D. bryoniae (OK 963096) in vitro and in vivo was 5.0 and 5.5, respectively (Fig. 6A and B). PG obtained both in vitro and in vivo showed some residual activity between $\mathrm{pH} 8$ and 12 . PG from decayed tissue showed some activity at $\mathrm{pH} 2$ to 3, but no PG activity was detected at or below $\mathrm{pH} 3$ from shake culture.

Using PG extracted from decayed fruit
(10 days postpollination) and fungal culture filtrate ( 10 days after inoculation), the mode of action of PG activity was determined by assaying viscosity reduction and the release of reducing groups. Hydrolysis at $50 \%$ viscosity reduction was 2.7 and $12.1 \%$ for PG from shake culture and decayed tissue, respectively. These results were further supported by reducing group analysis (Fig. 7A and 7B). The reducing groups at time zero incubation were original residues from PG samples. For the reaction of polygalacturonic acid plus a fungal PG sample from shake culture, mono-, di-, and tri-galacturonic acids, as well as oligomers, gradually increased with increased incubation time from 0.5 to $4 \mathrm{~h}$ (Fig. 7A). This suggested that PG isozymes produced in vitro were predominated by endo-PG activity. In contrast, the hydrolytic products of the reaction of polygalacturonic acid with a PG sample extracted from decayed fruit were predominated by monomers with some dimers, trimers, and oligomers during an incubation period of 0.5 to $4.0 \mathrm{~h}$ (Fig. 7B). Monomers increased with the extension of incubation time. A similar pattern of hydrolytic products was also observed with PG extracted from decayed tissue of 50day-old fruit (data not shown). This implied that PG isozymes produced by $D$. bryoniae in vivo were predominated by an exo-mode of activity.

\section{DISCUSSION}

The symptom characteristics of black rot on cantaloupe have not been adequately
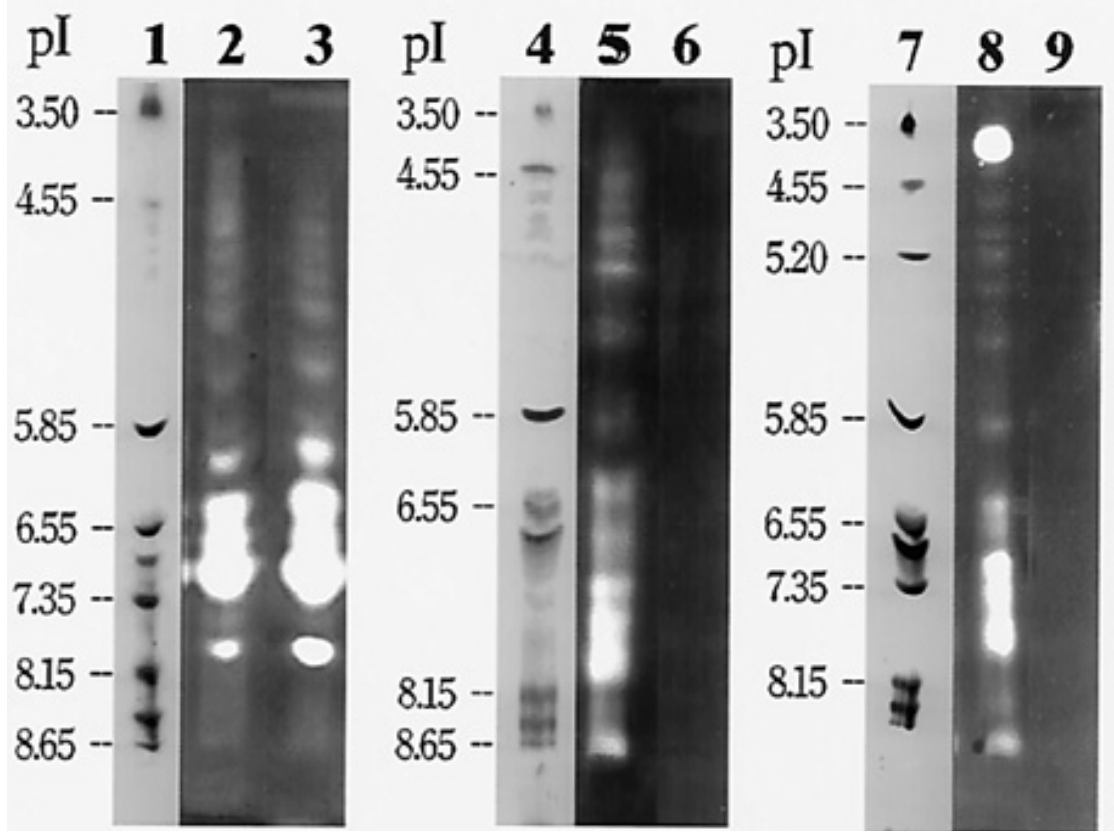

Fig. 5. Isoelectric focusing (IEF) gels illustrating polygalacturonase (PG) isozymes of Didymella bryoniae (OK 963096) detected from shake culture and cantaloupe fruit decayed by $D$. bryoniae. Lanes 1, 4, and 7, pI markers; lanes 2 and 3, PG isozymes of D. bryoniae detected from 10-day-old shake culture using polygalacturonic acid and pectin, respectively; lanes 5 and $8, D$. bryoniae PG isozymes detected from decayed fruit at 10 and 50 days postpollination, respectively; lanes 6 and 9 , protein extracts from healthy fruit at 10 and 50 days postpollination, respectively.

described in the literature. The black discoloration associated with the common name of the disease on fruit is not normally observed until fruit are near maturity. Consequently, field diagnosis of black rot of cantaloupe can be extremely difficult. The disease has many characteristics similar to those of Fusarium fruit rot (8). Both diseases are associated with net development, cause a fissure in the epidermis of the fruit, may produce a green island around the lesion, and produce a shallow reddish brown dry lesion. They differ in that the tan tissue surrounding Fusarium fruit rot lesions is often raised, whereas the tan tissue surrounding black rot lesions is not. However, these differences are subtle and not reliable for field identification. The internal lesions caused by $D$. bryoniae are often asymmetrical, with lesions becoming black with a white halo at the leading edge. Internal lesions caused by $F$. semitectum are symmetrical with a brown center and a white halo at the leading edge. The black discoloration is the most diagnostic feature of black rot observed in the latter part of the season.

Infection of cantaloupe fruit by $D$. bryoniae appears to occur primarily through the undeveloped net. Depending on environmental conditions, initial stages of epidermal splitting of cantaloupe fruit begin at 12 to 13 days postpollination (4). Net tissue derives from a subepidermal periderm that is a lenticular-shaped structure formed
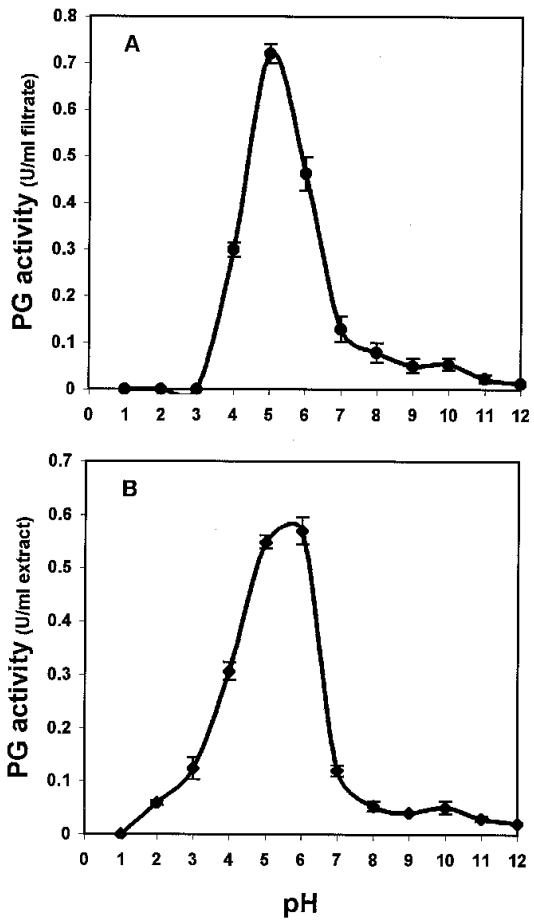

Fig. 6. Effect of $\mathrm{pH}$ on the activity of polygalacturonase produced by Didymella bryoniae (OK 963096) (A) in shake culture using pectin as the sole carbon source, and (B) in decayed cantaloupe fruit. Bars indicate standard errors of four replicates. 
by meristematic activity of phellogen cells and complementary tissue containing intercellular spaces (41). Once the net is fully formed (25 to 30 days postpollination), resistance to infection appears to increase $(4,16)$. In the spring of 1997 , some cantaloupe fields had $100 \%$ incidence of fruit rot in the LRGV of Texas. While some cantaloupe fruit had more than 400 lesions, black rot lesions. When the lesions were observed on honeydew fruit, they generally occurred at the stylar end. This observation further supports the hypothesis that the vides an important infection avenue for $D$. bryoniae. D. bryoniae infects cucumber fruit primarily through stomates and/or wounds, but not directly $(18,37)$. Van Steekelenburg (37) noted that infection percentages increased with increased depth of wounding of cucumber fruit. Internal infection of squash and cucumber fruit by $D$. bryoniae was achieved via the flowers $(11,17,38)$. Our survey of immature cantaloupe fruit (before net formation) showed that internal decay frequently occurred at the blossom end, suggesting that infection the nonnetted honeydew fruit rarely had netting formation in cantaloupe fruit pro-

of cantaloupe fruit may be through flower parts also.

Hadfield et al. (20) recently reported that three cDNA clones with significant homology to other cloned PGs were isolated from the melon cultivar Charentais, and their expression correlates temporally with the depolymerization of water-soluble pectins and an increase in pectin-degrading enzyme activity during fruit ripening. Under our testing conditions, PG activity was not detected from healthy fruit at developmental stages of 10 to 50 days postpollination, which is consistent with previous reports $(21,26,28,32,43)$. Consequently, PG detected from decayed cantaloupe fruit was considered to be of fungal origin.

PG has been implicated in the pathogenic processes of a number of hostpathogen systems, particularly in diseases characterized by tissue maceration or soft rot $(2,3,14)$. In the current study, $D$. bryoniae produced multiple PG isozymes in cantaloupe fruit and shake culture. Other workers have also reported in vitro or in vivo PG production by $D$. bryoniae $(6,12,15,22,33)$. In the present study, a significant correlation $(r=0.72)$ between

\section{A. In vitro}

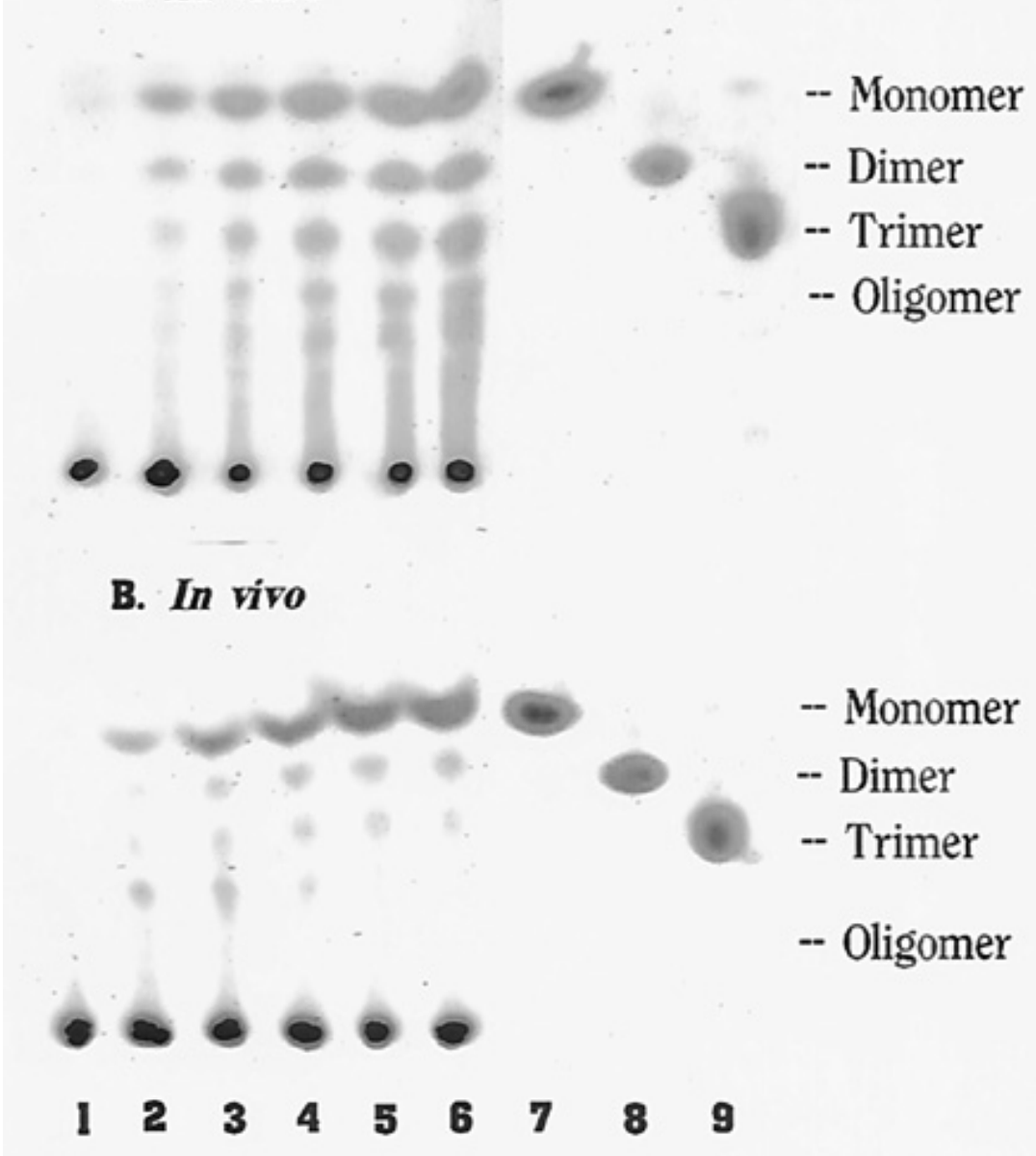

Fig. 7. Thin-layer chromatography of products hydrolized by polygalacturonase (PG) produced by Didymella bryoniae (OK 963096) (A) in shake culture using pectin as the sole carbon source, and (B) in decayed cantaloupe fruit (10 days postpollination). Lanes 1 to 6 , hydrolysis products after incubation of the PG sample with polygalacturonic acid at $0,0.5,1,2,3$, and $4 \mathrm{~h}$, respectively. Lanes 7 to 9 , mono-, di- and tri-galacturonic acid standards, respectively. lesion area and PG activity in decayed cantaloupe fruit tissue was demonstrated. Curren (15) reported that PG seemed to be an important enzyme involved in the breakdown of squash fruit by $D$. bryoniae. Chilosi and Magro (12) reported that a $D$. bryoniae isolate produced pectin lyase (PNL) and pectin methyl esterase (PME) but no PG in diseased hypocotyl tissue of melon. They noted that PNL activity was highly correlated $(r=0.91)$ with disease severity and suggested that it was the principal pectolytic enzyme associated with pathogenesis in the hypocotyl of melon seedlings. However, Chilosi and Magro (12) found only one inducible PG isozyme in culture filtrates. In addition to PG production, D. bryoniae produced the cell wall-degrading enzymes PME and cellulase $(\mathrm{Cx})$ in liquid culture and in decayed squash fruit, but lacked significant endopectic trans-eliminase activity in squash (15). Bruton et al. (6) reported $\mathrm{Cx}, \beta$-galactosidase, and PG production (in vitro) by a $D$. bryoniae isolate involved in vine decline of cantaloupe. Consequently, the relationships between the production of cell wall-degrading enzymes by $D$. bryoniae and the role of the enzymes in fungal pathogenesis and tissue maceration requires further study.

The capacity of fungal pathogens to produce multiple PG isozymes may be an advantage in their adaptation, versatility, and virulence. $D$. bryoniae produced multiple PG isozymes with a broad range of $\mathrm{pI}$ values, both in shake culture and in decayed cantaloupe fruit. PG isozyme patterns of $D$. bryoniae observed from shake culture using pectin or polygalacturonic acid as the sole carbon source were different from those detected from decayed fruit. The number of PG isozymes in decayed tissue obtained from 10- through 50-dayold fruit was similar, but a PG isozyme with pI 4.2 was only observed from decayed tissue of 50-day-old fruit. Although an additional fungal PG isozyme at pI 4.2 was observed from 50-day-old fruit, total fungal PG activity in 10-day-old fruit was still much greater than in 50-day-old fruit. This indicates that developmental stages of cantaloupe fruit primarily affect total fungal PG activity with little effect on the number of PG isozymes. Curren (15) reported that the optimum $\mathrm{pH}$ for $D$. bryoniae PG activity was 4.0, but our experiments demonstrated that the optimum $\mathrm{pH}$ 's for $D$. bryoniae PG activity produced in shake culture and decayed fruit were 5.0 and 5.5, respectively. The difference in optimum $\mathrm{pH}$ of $D$. bryoniae PG activity between our study and the previous report may be due to different fungal isolates and test conditions. D. bryoniae isolates are known to exhibit differences in pathogenicity, virulence, and other genetic attributes $(23,37)$.

In this study, PG isozymes produced by D. bryoniae in pectin shake culture exhib- 
ited a mixture of endo- and exo-activity. In contrast, PG extract from decayed fruit (10 or 50 days postpollination) were predominated by exo-activity. These modes of action of PG from in vitro and in vivo sources were verified with two additional D. bryoniae isolates (data not shown). This suggests that the endo-PG isozymes may be suppressed or not be induced by physiological factors in cantaloupe fruit. The endo-PG generally is more efficient to depolymerize pectic substrates and to macerate plant tissue compared with exo-PG (3). Phomopsis cucurbitae, another cantaloupe fruit-rotting fungus, produces predominately endo-PG activity (B. D. Bruton and J. X. Zhang, unpublished data) and causes a more aggressive decay in mature cantaloupe fruit than D. bryoniae (44). $P$. cucurbitae produces a soft and watersoaked lesion, whereas $D$. bryoniae produces a relative dry lesion on mature fruit. The decay caused by $P$. cucurbitae on 40day-old cantaloupe fruit was 2.2 times greater than that caused by $D$. bryoniae (44). Consequently, the difference in aggressiveness between these two fruit rot pathogens may be due to the fact that $P$. cucurbitae produces predominately endoPG, while $D$. bryoniae produces predominately exo-PG in mature cantaloupe fruit.

This study demonstrated that cantaloupe fruit developmental stage was related to decay susceptibility to $D$. bryoniae. Fruit at 10 days postpollination were the most susceptible compared with fruit at 20,30, 40, or 50 days postpollination. Approximately $27 \%$ more decay occurred in 10-day-old fruit than in fruit at later stages of development. Other studies with squash (47) and watermelon fruit (1) have shown that immature fruit were more susceptible to black rot than more mature fruit. In contrast, $P$. cucurbitae is a latent infection fungus that infects cantaloupe fruit during net formation and goes dormant until the fruit ripen $(4,5)$. It has been suggested that these latent infections may be due to substrate specificity or inhibitors present in cantaloupe fruit tissue $(7,43)$. de Neergaard (17) suggested that a delay in the onset of black rot caused by $D$. bryoniae in cucumber fruit may be associated with the accumulation of phenolic compounds. Kennedy et al. (24) noted that peroxidase activity was low in cantaloupe fruit in 10- and 15-dayold fruit but increased substantially thereafter. Although some peroxidase isozymes have been shown to be antimicrobial (31), the relationship of fruit peroxidase and susceptibility to decay by $D$. bryoniae is unknown. The decay pattern caused by $D$. bryoniae on cantaloupe fruit appears to be unique, in that the fruit become more resistant with fruit maturity. Glucose and fructose levels are high in 10- to 20-dayold cantaloupe fruit, with dramatic increases in sucrose occurring as the fruit approach maturity $(9,26,35,40)$. Chiu and Walker (13) noted that germination of $D$. bryoniae spores was enhanced by increasing concentrations of glucose and inhibited by increasing concentrations of sucrose. The possible role of fruit sugars in susceptibility of cantaloupe fruit to decay by $D$. bryoniae requires examination.

\section{ACKNOWLEDGMENTS}

We thank Rick Houser, Diann Baze, and Anthony Dillard, biological research technicians at the South Central Agricultural Research Lab, USDA-ARS, Lane, Oklahoma, for technical support in this study. We also thank Tom Popham, Area Statistician, USDA-ARS, Stillwater, Oklahoma, for data analysis and Anthony Keinath, Peter Cotty, Tom Zitter, and William Conway for manuscript review.

\section{LITERATURE CITED}

1. Bala, G., and Hosein, F. 1985. Gummy stem blight of watermelon and its control. J. Agric. Soc. Trinidad Tobago 85:17-23.

2. Bateman, D. F., and Basham, H. G. 1976. Degradation of plant cell walls and membranes by microbial enzymes. Encycl. Plant Physiol. New Ser. 4:316-355.

3. Bateman, D. F., and Millar, R. L. 1966. Pectic enzymes in tissue degradation. Annu. Rev. Phytopathol. 4:119-146.

4. Bruton, B. D. 1995. Etiology, epidemiology, and control of muskmelon fruit rots. Pages 48-54 in: Cucurbitaceae '94. G. Lester and J. Dunlap, eds. Gateway Printing, Edinburg, TX.

5. Bruton, B. D. 1996. Phomopsis black rot and purple stem. Pages 52-53 in: Compendium of Cucurbit Diseases. T. A. Zitter, D. L. Hopkins, and C. E. Thomas, eds. American Phytopathological Society, St. Paul, MN.

6. Bruton, B. D., Biles, C. L., Cluck, T. W., and Garcia-Jimenez, J. 1996. Fungal enzymes associated with selected vine decline pathogens of cantaloupe. (Abstr.) Phytopathology 86:S104

7. Bruton, B. D., Conway, W. S., Gross, K. C., Zhang, J. X., Biles, C. L., and Sams, C. E. 1998. Polygalacturonase of a latent and wound postharvest fungal pathogen of muskmelon fruit. Postharvest Biol. Technol. 13:205-214.

8. Bruton, B. D., and Duthie, J. A. 1996. Fusarium rot. Pages 50-51 in: Compendium of Cucurbit Diseases. T. A. Zitter, D. L. Hopkins, and C. E. Thomas, eds. American Phytopathological Society, St. Paul, MN.

9. Bruton, B. D., Russo, V. M., Garcia-Jimenez, J., and Miller, M. E. 1998. Carbohydrate partitioning, cultural practices, and vine decline diseases of cucurbits. Pages 189-200 in: $\mathrm{Cu}-$ curbitaceae '98. J. McCreight, ed. Am. Soc. Hortic. Sci. Press, Alexandria, VA.

10. Bruton, B. D., Zhang, J. X., Miller, M. E., and Isakeit, T. 1998. Association of environmental conditions with gummy stem blight and black rot epidemics of muskmelon in Oklahoma and Texas. Pages 283-286 in: Proc. Annu. Hortic. Indus. Conf., 17th. B. D. McCraw, ed. Oklahoma State University, Stillwater, OK.

11. Cardoso, R. M. G., Figueiredo, M. B., Palazzo, D., and Martinez, J. A. 1974. Epidemiology of fruit rot [Mycosphaerella melonis, (Pass) Chiu \& J. C. Walker] on Italian squash (Cucurbita pepo L.). Arq. Inst. Biol. Sao Paulo 41:35-37.

12. Chilosi, G., and Magro, P. 1998. Pectolytic enzymes produced in vitro and during colonization of melon tissues by Didymella bryoniae. Plant Pathol. 47:700-705.

13. Chiu, W. F., and Walker, J. C. 1949. Physiology and pathology of the cucurbit black-rot fungus. J. Agric. Res. 78:589-615.

14. Collmer, A., and Keen, N. T. 1986. The role of pectic enzymes in plant pathogenesis.
Annu. Rev. Phytopathol. 24:383-409.

15. Curren, T. 1969. Pectic and cellulolytic enzymes produced by Mycosphaerella citrullina and their relation to black rot of squash. Can. J. Bot. 47:791-794.

16. Davis, G. N., Whitaker, T. W., Bohn, G. W. and Kasmire, R. F. 1965. Muskmelon production in California. Calif. Agric. Exp. Stn Bull. 536.

17. de Neergaard, E. 1989. Histological investigation of flower parts of cucumber infected by Didymella bryoniae. Can. J. Plant Pathol. 11:28-38.

18. de Neergaard, E. 1989. Studies of Didymella bryoniae (Auersw.) Rehm: Development in the host. J. Phytopathol. 127:107-115.

19. Gross, K. C. 1982. A rapid and sensitive spectrophotometric method for assaying polygalacturonase using 2-cyanoacetamide. HortScience 17:933-934

20. Hadfield, K. A., Rose, J. K. C., Yaver, D. S., Berka, R. M., and Bennett, A. B. 1998. Polygalacturonase gene expression in ripe melon fruit supports a role for polygalacturonase in ripening-associated pectin disassembly. Plant Physiol. 117:363-373.

21. Hobson, G. E. 1962. Determination of polygalacturonase in fruits. Nature 195:804-805.

22. Hsieh, W. H., and Huang, J. W. 1985. Physiology and varietal reaction of gummy stem blight fungus of cucurbits. Plant Prot. Bull. (Taiwan) 27:325-331.

23. Keinath, A. P., Farnham, M. W., and Zitter, T. A. 1995. Morphological, pathological, and genetic differentiation of Didymella bryoniae and Phoma spp. isolated from cucurbits. Phytopathology 85:364-369.

24. Kennedy, K., Biles, C., Bruton, B., and Zhang, J. 1997. Peroxidase activity and isozymes of cantaloupe tissue. (Abstr.) Proc. Okla. Acad. Sci. 77:133.

25. Leski, B. 1984. Black fruit and stem rot caused by Didymella bryoniae an important disease of glasshouse cucumber new to $\mathrm{Po}-$ land. Acta Hortic. 156:245-250.

26. Lester, G. E., and Dunlap, J. R. 1985. Physiological changes during development and ripening of 'Perlita' muskmelon fruits. Sci. Hortic. 26:323-331.

27. Martinson, C., and Baker, R. 1962. Increasing relative frequency of specific fungus isolations with soil microbiological sampling tubes. Phytopathology 52:619-621.

28. McCollum, T. G., Huber, D. J., and Cantiliffe, D. 1989. Modification of polyuronides and hemicelluloses during muskmelon fruit softing. Physiol. Plant. 76:303-308.

29. McGrath, D. F., Vawdrey, L., and Walker, L. O. 1993. Resistance to gummy stem blight in muskmelon. HortScience 28:930-931.

30. Miller, M. E., Isakeit, T., Zhang, J. X., and Bruton, B. D. 1997. Gummy stem blight and black rot of melons. Pages 1-19 in: Melon Production System in Southern Texas. M. E. Miller, ed. Agric. Res. Ext. Cent. Annu. Res. Rep., Texas A\&M Univ. Syst., Weslaco, TX.

31. Peng, M., and Kuc, J. 1992. Peroxidase-generated hydrogen peroxide as a source of antifungal activity in vitro and on tobacco leaf disks. Phytopathology 82:696-699.

32. Ranwala, A. P., Suematsu, C., and Masuda, H. 1992. The role of $\beta$-galactosidase in the modification of cell wall components during muskmelon fruit ripening. Plant Physiol 100:1318-1325.

33. Reshetnikova, A., and Uspenskaya, G. D. 1978. Pectolytic enzymes of fungi of the genus Askochyta lib. Biol. Nauki (Russia) 6:97100.

34. Ried, J. L., and Collmer, A. 1985. Activity stain for rapid characterization of pectic enzymes in isoelectric focusing and sodium dodecyl sulfate-polyacrylamide gels. Appl. En- 
viron. Microbiol. 50:615-622.

35. Schaffer, A. A., Pharr, D. M., and Madore, M. A. 1997. Cucurbits. Pages 729-757 in: Photoassimilate Distribution in Plants and Crops: Source-Sink Relationships. E. Zamski and A. A. Schaffer, eds. Marcel Dekker Inc., New York.

36. Sitterly, W. R., and Keinath, A. P. 1996. Gummy stem blight. Pages 27-28 in: Compendium of Cucurbit Diseases. T. A. Zitter, D. L. Hopkins, and C. E. Thomas, eds. American Phytopathological Society, St. Paul, MN.

37. Van Steekelenburg, N. A. M. 1982. Factors influencing external fruit rot of cucumber caused by Didymella bryoniae. Neth. J. Plant Pathol. 88:47-56.

38. Van Steekelenburg, N. A. M. 1986. Factors influencing internal fruit rot of cucumber caused by Didymella bryoniae. Neth. J. Plant Pathol. 92:81-91.

39. Vawdrey, L. L. 1994. Evaluation of fungicides and cultivars for control of gummy stem blight of rockmelon caused by Didymella bryoniae. Aust. J. Exp. Agric. 34:1191-1195.

40. Wang, Y. M., Wyllie, S. G., and Leach, D. N. 1996. Chemical changes during the development and ripening of the fruit of Cucumis melo (Cv. Makdimon). J. Agric. Food Chem. 44:210-216.

41. Webster, B. D., and Craig, M. E. 1976. Net morphogenesis and characteristics of the surface of muskmelon fruit. J. Am. Soc. Hortic. Sci. 101:412-415.

42. Yao, C. L., Conway, W. S., and Sams, C. E. 1996. Purification and characterization of a polygalacturonase produced by Penicillium expansum in apple fruit. Phytopathology 86:1160-1166.

43. Zhang, J. X., Bruton, B. D., and Biles, C. L. 1997. Polygalacturonase isozymes produced by Phomopsis cucurbitae in relation to postharvest decay of cantaloupe fruit. Phytopathology 87:1020-1025.

44. Zhang, J. X., Bruton, B. D., Miller, M. E., and
Isakeit, T. 1998. Comparison of cantaloupe fruit decays caused by Didymella bryoniae and Phomopsis cucurbitae at different fruit developmental stages. Pages 8-16 in: 1998 Annual Report: Melon Production System in South Texas. M. E. Miller, ed. Agric. Res.

Ext. Cent. Annu. Res. Rep., Texas A\&M Univ. Syst., Weslaco, TX.

45. Zhang, Y. P., Kyle, M., and Anagnostou, K. and Zitter, T. A. 1997. Screening melon (Cucumis melo) for resistance to gummy stem blight in the greenhouse and field. HortScience 32:117-121.

46. Zitter, T. A. 1996. Black rot. Page 48 in: Compendium of Cucurbit Diseases. T. A. Zitter, D. L. Hopkins, and C. E. Thomas, eds. American Phytopathological Society, St. Paul, MN.

47. Zitter, T. A., and Drennan, J. L. 1995. Rind maturity and susceptibility of butternu squash to Didymella bryoniae. Cucurbit Genet. Coop. 18:62-63. 